\title{
An Unusual Combination of Klinefelter Syndrome and Growth Hormone Deficiency in a Prepubertal Child
}

\author{
Jayanthy Ramesh1, Mudiganti Nagasatyavani2, Javvadii Venkateswarlu2, Jakka Nagender2 \\ ${ }^{1}$ Sai Institute of Endocrinology, Endocrinology, Hyderabad, India \\ 2Osmania Medical College and General Hospital, Endocrinology, Hyderabad, India
}

\section{ABSTRACT}

Klinefelter syndrome (KS) is the most common chromosomal aneuploidy in males. It is very difficult to diagnose this disorder in childhood due to absence of significant manifestations before puberty. These patients usually present with tall stature. We report a case of KS with short stature due to growth hormone deficiency. The boy's height was below the $3^{\text {rd }}$ centile with significant delay in bone age. He responded well to growth hormone injections. In view of mental subnormality karyotyping was done, which revealed KS (47XXY).

Key words: Short stature, Klinefelter syndrome, growth hormone deficiency

Conflict of interest: None declared

Received: 01.12.2013

Accepted: 08.04 .2014

\section{Introduction}

Klinefelter syndrome (KS) is the most common chromosomal aneuploidy in males. Also, it is the most common genetic cause of azoospermia (1). It is characterized by small testes, tall stature and mental subnormality. We report an unusual case of $\mathrm{KS}$ with growth hormone $(\mathrm{GH})$ deficiency and short stature.

\section{Case Report}

We report a 3-year-old male child who was referred by his pediatrician for short stature (Figure 1). He was born to parents with no consanguinity, at 36 weeks gestation, by vaginal delivery. His birth weight and length were normal.

The boy had delayed motor and language milestones. There was no history of recurrent infections or chronic systemic diseases. His height was $76 \mathrm{~cm}$ [height standard deviation score (SDS) -3.7, height age 1 year]. His body proportions were normal for his age. He had no midline facial defects, dysmorphic facies or bony defects. His external genitalia revealed microphallus (stretched penile length of 2 $\mathrm{cm}$, more than $2.5 \mathrm{SD}$ below the mean for the age) with normal external urethral meatus, well-formed scrotum, and palpable prepubertal testes. Other systems were normal. Bone age was delayed by 2 years (Figure 2). The base line investigations and thyroid profile were normal. Serum insulin-like growth factor-1 level was $52.6 \mathrm{ng} / \mathrm{mL}$ (agespecific normal range: $49-289 \mathrm{ng} / \mathrm{mL}$ ) which increased to $132 \mathrm{ng} / \mathrm{mL}$ following $\mathrm{GH}$ treatment. Clonidine-stimulated $\mathrm{GH}$ level was low $(0.8 \mathrm{ng} / \mathrm{mL})$ which confirmed $\mathrm{GH}$ deficiency.

\footnotetext{
Address for Correspondence

Mudiganti Nagasatyavani MD, Osmania Medical College and General Hospital, Endocrinology, Hyderabad, India

Phone: +91040 24653992 E-mail: drvsrm@gmail.com

(C) Journal of Clinical Research in Pediatric Endocrinology, Published by Galenos Publishing.
} 


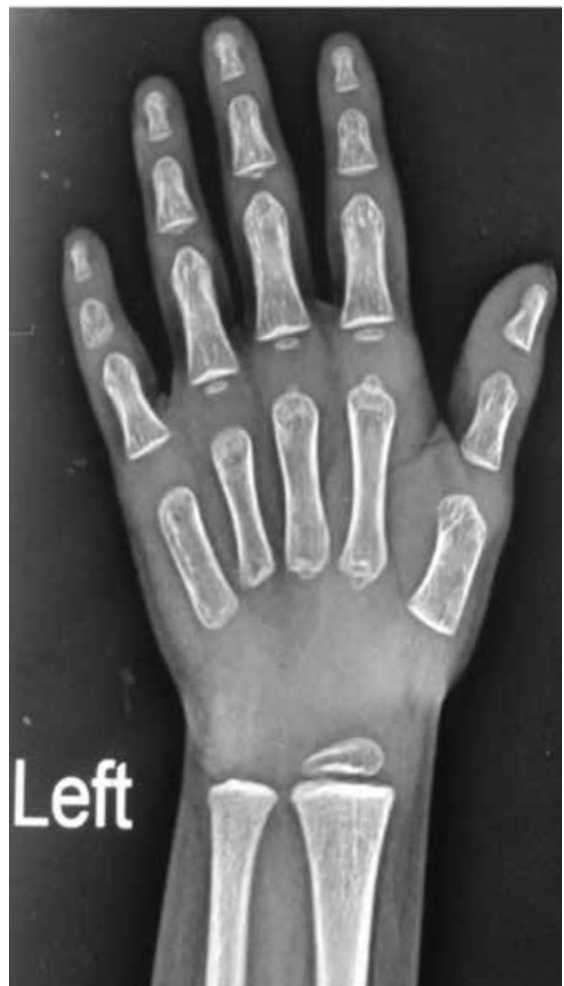

Figure 1. X-ray of the left hand and wrist showing a bone age of less than one year

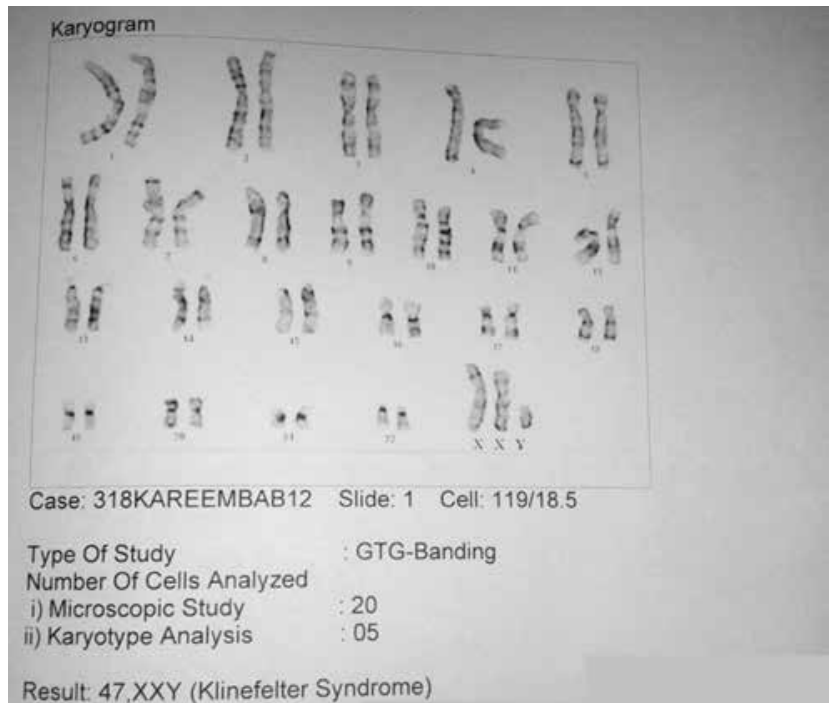

Figure 2. Karyotype showing $47 X X Y$

In view of developmental delay and mental subnormality, karyotyping was done and revealed a 47XXY pattern (Figure 2). Chromosomal microarray revealed multiple duplications on $X$ chromosome (of about $55.6 \mathrm{mb}$ at cytoband Xp22.33-p11.1, 6.4 mb at cytoband Xq12-q13.1, 27.5mb at cytobandXq13.1-q22.1 and 55.5mb at cytobandXq22.1-q28), implicating presence of an extra copy of $\mathrm{X}$ chromosomal complement resulting in $\mathrm{KS}$.

The boy was started on recombinant human $\mathrm{GH}$ injections subcutaneously. There were no local or general side effects. After 1 year of treatment, his height increased to $84 \mathrm{~cm}$ and height SDS improved from -3.7 to -2 . The patient is still receiving recombinant human $\mathrm{GH}$ with regular followup every 3 months for physical and auxological evaluation.

\section{Discussion}

Tall stature is one of the characteristic features of $\mathrm{KS}$. The clinical phenotype has traditionally been described as tall, with sparse body hair, gynecomastia, small testes and impaired verbal intelligence (2). It is not easy to diagnose KS in childhood because of the absence of significant manifestations before puberty (3). According to a large Danish registry study (4), only $10 \%$ of KS men are diagnosed before puberty and only $25 \%$ during their lifetime.

The association between $\mathrm{KS}$ and $\mathrm{GH}$ deficiency has been described in a small number of case reports, but the reason for such an association is not clearly known. Our patient was short due to $\mathrm{GH}$ deficiency which was thought to be due to pituitary hypoplasia. Pituitary imaging (MRI) was suggestive of anterior pituitary gland hypoplasia $(1.7 \mathrm{~mm})$. Other pituitary functions at this juncture were normal. The association of short stature with delayed bone age, hypoplastic pituitary gland and poor increase in $\mathrm{GH}$ level on stimulation tests is suggestive of an isolated $\mathrm{GH}$ deficiency. Richer et al (5) reported a few cases of KS with short stature due to presence of an $\mathrm{Xq}$ isochromosome. The present case is unique as it is associated with $\mathrm{GH}$ deficiency. So far, there are few reported cases of KS and short stature secondary to $\mathrm{GH}$ deficiency. Rossodivita et al (6) reported an 8-year-old boy with short stature and cryptorchidism who was later diagnosed to have KS and $\mathrm{GH}$ deficiency. Bahillo Curieses et al (7) reported a similar combination in a child receiving $\mathrm{GH}$ therapy when evaluated for delayed puberty, but the brain MRI was reported as normal in this patient. Ben-Skowronek et al (8) and Tori et al (9) also reported similar combination of KS and $\mathrm{GH}$ deficiency. The diagnosis of $\mathrm{KS}$ was made in most of the reported cases when the children failed to enter puberty. Our case is also unique as it was diagnosed in the prepubertal age.

In conclusion, by reporting the findings on this patient, we wish to emphasize the importance of $\mathrm{GH}$ testing in pediatric patients with $\mathrm{KS}$, short stature, and delayed bone age. 
Ramesh $\mathrm{J}$ et al.

Klinefelter Syndrome and Growth Hormone Deficiency

\section{References}

1. Tüttelmann F, Gromoll J. Novel genetic aspects of Klinefelter's syndrome. Mol Hum Reprod 2010;16:386-395. Epub 2010 Mar 12

2. Bojesen $\mathrm{A}, \mathrm{Gravholt} \mathrm{CH}$. Klinefelter syndrome in clinical practice. Nat Clin Pract Urol 2007;4:192-204.

3. Boudailliez B, Chaussain JL, Garnier P, Canlorbe P, Job JC. Le syndrome de Klinefelterchez 1 'enfant et a l'age de la puberte: exploration endocrini enne. Ann Pediatr 1981;28:195-201.

4. Bojesen A, Juul S, Gravholt CH. Prenatal and postnatal prevalence of Klinefelter syndrome: a NationalRegistry study. J Clin Endocrinol Metab 2003;88:622-626.

5. Richer CL, Bleau G, Chapdelaine A, Murer-Orlando $M$, Lemieux N, Cadotte M. A man with isochromosome $\mathrm{Xq}$
Klinefelter syndrome with lack of height increase and normal androgenization. Am J Med Genet 1989;32:42-44.

6. Rossodivita A, Colabucci F. Short stature in a patient with Klinefelter syndrome and growth hormone deficiency. Am J Med Genet 1994;49:244-246.

7. Bahílo-Curieses MP, Fournier-Carrera M, Morán-López J, Martínez-Sopena MJ. Klinefelter syndrome and short stature: an unusual combination. Endocrine 2011;39:294-295.

8. Ben-Skowronek I, Jaklinska T, Moczybroda M, Szewczyk L. A patient with Klinefelter' s syndrome and growth hormone deficiency. Pediatr Endocrinol Diabetes Metab 2010;16:55-57.

9. Tori $C$, Roe $C$. Klinefelter syndrome with partial deficiency of growth hormone. Rev Med Hered 1999;10:50-54. 